\title{
Enzymatic hydrophobization of jute fabrics and its effect on the mechanical and interfacial properties of jute/PP composites
}

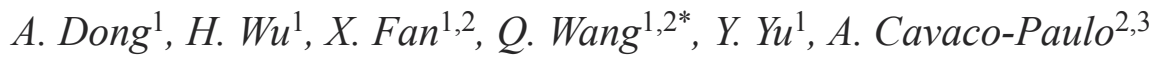 \\ ${ }^{1}$ Key Laboratory of Science and Technology of Eco-Textile, Ministry of Education, Jiangnan University, Wuxi, 214122 \\ Jiangsu, China \\ ${ }^{2}$ International Joint Research Laboratory for Textile and Fiber Bioprocesses, Jiangnan University, Wuxi, 214122 Jiangsu, \\ China \\ ${ }^{3}$ Centre of Biological Engineering, University of Minho, Campus de Gualtar, 4710-057 Braga, Portugal
}

Received 13 October 2015; accepted in revised form 14 December 2015

\begin{abstract}
In this work, a hydrophobic surface of lignocellulosic jute fabric was achieved via the laccase-mediated grafting of octadecylamine (OA) on lignin moieties of jute aiming to improve the interfacial compatibility with the hydrophobic polypropylene (PP) resins in the fiber-reinforced composites. Firstly, the surface and total elemental compositions of the modified jute fabrics were investigated by X-ray photoelectron spectroscopy (XPS) and elemental analysis, respectively. The increases in the surface $\mathrm{C} / \mathrm{O}$ ratio and total nitrogen content of jute fabrics after the laccase/OA treatment indicated that OA molecules were successfully grafted onto the jute surface mediated by laccase. The grafting percentage of OA on jute fabrics was $0.96 \%$. The surface hydrophobicity of jute fabrics with static contact angle of $112.5^{\circ}$, advancing angle of $116.4^{\circ}$ and receding angle of $42.7^{\circ}$ supported the presence of nonpolar alkyl chains on the jute surface after the laccase-mediated OA-grafting. The tensile strength, tensile modulus as well as the elongation at break of the hydrophobized jute/PP composites were increased. The fracture surface of the composites became neat and the jute fibers on the section surface were surrounded by PP resins closely, which suggested better interfacial adhesion between the jute reinforcement and the PP resin.
\end{abstract}

Keywords: polymer composites, jute fiber reinforcement, laccase, hydrophobization, interfacial compatibility

\section{Introduction}

The application of natural plant fibers such as ramie fiber, jute fiber, sisal fiber and bamboo fiber to replace glass fiber and synthetic fibers as the reinforcement of resin matrix composites has drawn a wide public attention in recent decades [1,2]. These natural fibers can not only meet the property requirements for reinforced materials in composites but also have the merits of low cost, abundance, light weight, biodegradability and renewability. However, plant fibers mainly consisting of cellulose, hemicellulose and lignin always exhibit strong hydrophilicity and high moisture absorption. This deteriorates the inter- facial compatibility with hydrophobic resins and then the mechanical properties of the fiber-reinforced composites [3, 4]. In order to obtain high-performance composite materials, surface modification of the fiber reinforcements including various physical and chemical processing technologies proved to be an effective and practical method.

However, these traditional approaches were demonstrated to have some inherent shortcomings. The physical methods may be difficult to industrialize and can seriously deteriorate the mechanical properties of the natural fibers, especially the tensile strength $[5,6]$. The grafting modification with vinyl mono-

\footnotetext{
${ }^{*}$ Corresponding author, e-mail: qiang_wang@163.com

(C) BME-PT
} 
mers can increase the hydrophobicity of the fibers and improve the compatibility with hydrophobic resin matrix [7]. But it is also known that the homopolymerization will occur inevitably. Although the treatment of fibers with organic silane coupling agents has achieved much success in improving the surface hydrophobicity, it usually involves complicated multi-step processes and waste disposal of emulsifiers present on the surface after the treatment $[8,9]$. Moreover, the current increasing concern on the environmental protection also hinders the industrial application of silicon compounds. Therefore, it has great practical significance to explore new modification methods for the natural fibers.

Nowadays, the use of enzymes as important biotechnological catalysts in the surface processing of lignocellulosic polymers is increasing dramatically [10-14]. Enzymatic processes have advantages such as specificity, effectiveness, eco-friendly nature and working in mild conditions as compared to the conventional methods. Laccases (EC 1.10.3.2, benzenediol:oxygen oxidoreductase) are the most investigated enzymes in this field. They are multi-copper glycoproteins that catalyze the monoeletronic oxidation of phenols and aromatic amines to reactive radicals and simultaneously reduce molecular oxygen to water in a redox reaction $[15,16]$. Studies show that lignin is a suitable substrate for laccase and the phenolic sites of lignin molecules can be oxidized to phenoxyl radicals by laccase [17]. With the laccasecatalyzed oxidation of lignin moieties rich on the surface, the lignocellulosic materials could be activated to create a radical-rich reactive surface to which oxidized (radical-containing) phenolic molecules of interest by laccase simultaneously can be grafted [18-23]. Natural jute fiber, a widely used lignocellulosic bioresource with lignin content of 14$20 \%$, also has the potential to be modified by this green biotechnology for endowing it with better performance or novel functions [24, 25]. Besides the use of phenolic monomers in the enzymatic grafting reactions, aliphatic amines were first reported by Kudanga et al. [26] to couple with lignin model molecules mediated by laccase. However, as far as our knowledge goes, no attempt has seemingly been made before for the surface hydrophobization of jute fibers by the laccase-mediated grafting of amine monomers to increase the interfacial compatibility with hydrophobic resins in composites.

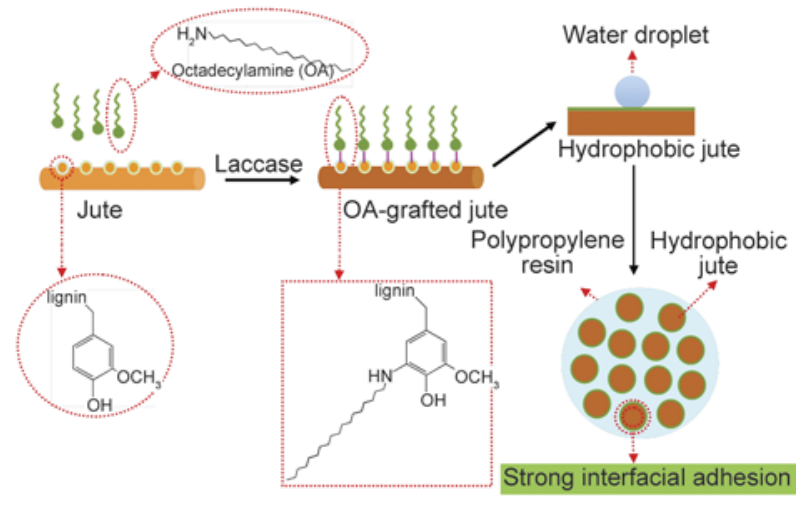

Figure 1. Schematic illustration of the enzymatic grafting of octadecylamine to lignins on the jute surface aiming to improve the interfacial adhesion with polypropylene resins

In the present work, lignocellulosic jute fabrics were modified to be hydrophobic via the laccase-mediated grafting of octadecylamine (OA) on the lignin moieties and then the hydrophobized jute was used as the reinforced material of the polypropylene (PP) matrix composites to improve the interfacial compatibility between the fiber reinforcements and the hydrophobic resins as shown in Figure 1. Initially, the surface elemental composition of jute fabrics was characterized by XPS and the grafting percentage of OA on jute fabrics was determined by elemental analysis. Then, the surface hydrophobicity of jute fabrics was investigated in terms of static and dynamic contact angles. Further, the pyrolytic characteristics of jute fabrics were studied by means of thermogravimetry (TGA) and differential thermogravimetry (DTG) measurements. Lastly, the tensile properties, dynamic mechanical performances and fracture surface of jute fabric/ PP composites were analyzed.

\section{Experimental}

\subsection{Materials and reagents}

Laccase from Trametes Versicolor was provided by Sigma-Aldrich. The $100 \%$ raw jute fabrics $\left(427 \mathrm{~g} / \mathrm{m}^{2}\right)$, with a 7/7 (warp/weft) $\mathrm{cm}^{-1}$ fabric density, were supplied by Longtai Weaving Co. Ltd. (Changshu, China). Octadecylamine (OA) with $90 \%$ purity was obtained from Aladdin Technology Co. Ltd. (Shanghai, China). Polypropylene (PP) melt-blown nonwoven cloths $\left(200 \mathrm{~g} / \mathrm{m}^{2}\right)$ were purchased from Yonghui Textile Technology Co. Ltd. (Yangzhou, China). All the other chemicals used in this study were commercially available and analytical grade. 


\subsection{Laccase assay}

The activity of laccase was measured using a UV-Vis spectrophotometer by monitoring the oxidation of 2 , 2'-azino-bis-(3-ethylthiazoline-6-sulfonate) (ABTS; $\left.\varepsilon_{420}=36000 \mathrm{M}^{-1} \cdot \mathrm{cm}^{-1}\right)$ as the substrate at $420 \mathrm{~nm}$ in $80 / 20(\mathrm{v} / \mathrm{v}, \%) 0.2 \mathrm{M}$ acetate buffer $(\mathrm{pH} 4) / \mathrm{EtOH}$ mixtures at $50^{\circ} \mathrm{C}$. The enzyme activity was expressed in units defined as micromoles of ABTS oxidized per minute [27].

\subsection{Pretreatment of jute fabrics}

Jute fabrics ( $500 \mathrm{~mm}$ long and $100 \mathrm{~mm}$ wide) were Soxhlet-extracted with benzene/ethanol $(\mathrm{v} / \mathrm{v}, 2: 1)$ for $12 \mathrm{~h}$ to remove the lipophilic extractives and then boiled with distilled water for $3 \mathrm{~h}$ to remove the water-soluble fractions. As a result, the oxidation of substrate molecules by laccase and the analysis of modified fabrics could be carried out without interference.

\subsection{Enzymatic grafting of jute fabrics with OA monomers}

Jute fabrics of $1 \mathrm{~g}$ were incubated in $50 \mathrm{~mL} \mathrm{80/20}$ (v/v, \%) $0.2 \mathrm{M}$ acetate buffer $(\mathrm{pH} 4) / \mathrm{EtOH}$ solutions with $1.5 \mathrm{U} / \mathrm{mL}$ laccase and $20 \mathrm{mM} \mathrm{OA}$. The reaction was carried out at $50^{\circ} \mathrm{C}$ for $24 \mathrm{~h}$ in a shaking bath. Afterwards, the fabrics were washed twice with distilled water at $50^{\circ} \mathrm{C}$ for $20 \mathrm{~min}$ and then extracted with benzene/ethanol (v/v, 2:1) for $12 \mathrm{~h}$ to remove the absorbed (non-covalent bonding) OA monomers. Control and laccase-treated samples followed the same treatment condition as mentioned above.

\subsection{XPS measurement of jute fabrics}

X-ray photoelectron spectroscopy (XPS) experiments were performed on a RBD upgraded PHI5000C ESCA system (Perkin Elmer) with $\mathrm{Mg} \mathrm{K} \alpha$ radiation $(h v=1253.6 \mathrm{eV})$. The $\mathrm{X}$-ray anode was run at $250 \mathrm{~W}$, and the high voltage was maintained at $14.0 \mathrm{kV}$ with a detection angle of $54^{\circ}$. The whole spectra $(0-1100 \mathrm{eV})$ and the narrow spectra of all the elements with much high resolution were both recorded using RBD 147 interface (RBD Enterprises, USA) through AugerScan 3.21 software. Binding energies were calibrated with the contaminant carbon $\left(\mathrm{C}_{1 \mathrm{~s}}=284.6 \mathrm{eV}\right)$.

\subsection{Elemental analysis of jute fabrics}

The total carbon, hydrogen and nitrogen contents of the jute fabric samples were determined in an ele- mental analyzer (Elementar Vario EL III, Germany).

\subsection{Determination of grafting percentage on jute fabrics}

The grafting percentage ( $G p$ ) of the enzymatic OAgrafting onto jute fabrics was calculated from the total nitrogen content of samples using Equation (1):

$G p[\%]=\frac{N_{\mathrm{g}}-N_{\mathrm{c}}}{14} \cdot M_{\mathrm{C}_{18} \mathrm{H}_{39} \mathrm{~N}}$

where $N_{\mathrm{g}}$ is the nitrogen content of the grafted jute fabrics [\%], $N_{\mathrm{c}}$ is the nitrogen content of the control jute fabrics [\%], and $M$ is the molar mass of OA molecules $\left[\mathrm{g} \cdot \mathrm{mol}^{-1}\right]$.

\subsection{Contact angle measurements of jute fabrics}

Before the contact angle measurements, jute fabric samples were conditioned to equilibrium moisture content (ca. 6.4\%) in a constant temperature and humidity equipment $\left(21^{\circ} \mathrm{C}, 65 \% \mathrm{RH}\right)$. The static contact angle of jute fabrics was determined in $3 \mathrm{~s}$ after water drop deposition using a JC2000D4 contact angle meter (Zhongchen, Shanghai). For each sample, five spots were measured, and then the results were averaged.

The dynamic contact angle of jute fabrics was measured by the Wilhelmy technique on a DCAT-21 interfacial tension meter (Dataphysics, Germany). Samples with a thickness of $1.2 \mathrm{~mm}$ and a width of $15 \mathrm{~mm}$ were immersed into and withdrawn out of water while simultaneously measuring the force acting on the sample at $20^{\circ} \mathrm{C}$. The advancing and receding contact angles could then be calculated from the recorded force curve. Three samples were taken for each treatment and the results were averaged.

\subsection{Thermal analysis of jute fabrics}

The thermogravimetric analysis (TGA) of the jute fabric samples was conducted on a Q500 thermogravimetric analyzer (TA Instruments, USA) in the range of $30-700^{\circ} \mathrm{C}$ with a heating rate of $20^{\circ} \mathrm{C} / \mathrm{min}$.

\subsection{Preparation of jute fabric/PP composites}

First, jute fabrics (1.2 mm thick after the enzymatic treatments) and PP foils ( $0.6 \mathrm{~mm}$ thick) were cut into samples of $20 \mathrm{~mm}$ width and $100 \mathrm{~mm}$ length. Then, the jute fabric/PP complex was prepared by the successive laying with two layers of jute fabrics and three layers of PP foils in a mass ratio of 1:1. 
Finally, the composite samples were compressed in the steel mould ( $1 \mathrm{~mm}$ thick) at $180^{\circ} \mathrm{C}$ in 10 ton pressure for $10 \mathrm{~min}$.

\subsection{Tensile measurement of jute fabric/PP composites}

The tensile properties of the jute fabric/PP composites were determined using a KD111-5 microcomputer-controlled electronic universal testing machine. The composite samples had a dimension of $100 \mathrm{~mm}$ (length) $\times 20 \mathrm{~mm}$ (width). The average thickness of the composites was $1 \mathrm{~mm}$ with a random error of $<0.1 \mathrm{~mm}$. The gauge length was set at $60 \mathrm{~mm}$, and the testing speed was $2 \mathrm{~mm} / \mathrm{min}$. A stress-strain curve of the composites and the data of the breaking strength, modulus and elongation were recorded. All measurements were performed using at least five samples.

\subsection{Fracture analysis of jute fabric/PP composites}

The fracture sections of the jute fabric-reinforced PP composites were scanned using a SU1510 scanning electron microscope (SEM, Hitachi, Japan) under $5.00 \mathrm{k}$ voltages at $2.00 \mathrm{k}$ magnification.

\subsection{Dynamic mechanical analysis (DMA) of the jute fabric/PP composites}

A Q800 DMA analyzer (TA Instruments, USA) was used for the evaluation of storage modulus and loss modulus. A three-point bending mode was employed. The samples were tested in a fixed frequency of $1.0 \mathrm{~Hz}$ and a heating rate of $5{ }^{\circ} \mathrm{C} / \mathrm{min}$. The samples were evaluated in the range from 30 to $160^{\circ} \mathrm{C}$. Each sample had a thickness of $1 \pm 0.1 \mathrm{~mm}$, a width of $13 \mathrm{~mm}$ and a length of $60 \mathrm{~mm}$.

\section{Results and discussion}

\subsection{XPS analysis of jute fabric surface}

XPS analysis of material surfaces could provide the surface information of the elemental composition as well as the bonding states of atoms. In this study, XPS spectroscopy was used to understand efficiently the changes in the surface chemistry of jute fabrics resulted from the laccase/OA treatment. Table 1 showed a general survey of the surface atomic composition for the treated jute fabric samples. The surface $\mathrm{C} / \mathrm{O}$ ratio of the laccase/OA-treated jute (3.4) was increased compared with the laccase-treated jute (2.7) and the control jute (2.6). This could be attrib-
Table 1. Surface chemical composition of the treated jute fabric samples obtained by XPS analysis

\begin{tabular}{|l|c|c|c|c|}
\hline \multirow{2}{*}{\multicolumn{1}{|c|}{ Samples }} & \multicolumn{3}{c|}{ Elements } & \multirow{2}{*}{ C/O } \\
\cline { 2 - 4 } & $\mathbf{C}_{\mathbf{1 s}}$ & $\mathbf{O}_{\mathbf{1 s}}$ & Others & \\
\hline Control jute & 68.8 & 26.6 & 4.7 & 2.6 \\
\hline Laccase-treated jute & 68.5 & 25.5 & 6.0 & 2.7 \\
\hline Laccase/OA-treated jute & 73.3 & 21.7 & 5.0 & 3.4 \\
\hline
\end{tabular}

uted to the grafting of OA molecules onto the jute surface mediated by laccase, as the OA structure has a high carbon content of $93.9 \%$ without any oxygen atoms.

\subsection{Estimation of grafting percentage via elemental analysis}

The total nitrogen content of jute fabrics was measured by the elemental analyzer, from which the grafting percentage $(G p)$ of OA on jute fabrics could be calculated by using Equation (1). The total nitrogen, carbon, hydrogen, oxygen contents as well as the $\mathrm{C} / \mathrm{O}$ ratio of jute fabric samples after the laccase/ $\mathrm{OA}$ and control treatments were listed in Table 2. The total nitrogen content of the laccase/OA treated jute $(0.18 \%)$ was increased when contrasted with the control jute $(0.13 \%)$. The obtained $G p$ of the laccase-mediated OA-grafting reaction was $0.96 \%$. In addition, there also has an enhancement in the total $\mathrm{C} / \mathrm{O}$ ratio of the laccase/OA-treated jute fabrics, which indicated that the long alkyl chains of OA molecules were successfully incorporated to the jute surface via the laccase-mediated grafting in the laccase/OA treatment.

This eco-friendly enzymatic process provides an attractive alternative to the current methods for improving the surface hydrophobicity of jute fiber and other natural lignocellulosic fibers. Enzyme technologies are specific, effective, green and work in mild conditions in response to the shortcomings of traditional physical and chemical approaches. The monomers of the laccase-mediated grafting can be divided into two categories, phenolic compounds and amine compounds. It is generally reported that the laccase-mediated grafting of phenolic monomers

Table 2. Total elemental composition of jute fabrics after the laccase/OA and control treatments

\begin{tabular}{|l|c|c|c|c|c|}
\hline \multirow{2}{*}{ Treatments } & \multicolumn{4}{|c|}{ Element content } & \multirow{2}{*}{ C/O } \\
\cline { 2 - 5 } & $\mathbf{C}$ & $\mathbf{H}$ & $\mathbf{O}$ & $\mathbf{N}$ & \\
\hline Laccase/OA & 45.07 & 6.96 & 47.78 & 0.18 & 0.94 \\
\hline Control & 44.48 & 6.88 & 48.51 & 0.13 & 0.92 \\
\hline
\end{tabular}


onto lignocellulosic materials has been successfully achieved to endow such polymers with novel functions [18-25]. However, the homopolymerization of these phenols will occur inevitably accompanied with the desired enzymatic grafting reaction. By contrast, the amine compounds such as OA used in this study could not be polymerized or self-coupled by laccase and are considered as ideal monomers for the enzymatic grafting modification of natural lignocellulosic polymers.

\subsection{Effect of OA-grafting on surface hydrophobicity of jute fabrics}

Wettability of fibers is an important factor for the interfacial adhesion with the hydrophobic resin matrix in composites as well as the water absorption behavior of the composites [28]. The hydrophilic characteristics of jute fibers lead to poor wettability and weak interfacial bonding with resins and facilitate the intake of water when the composites were immersed in water, finally resulting in decreased mechanical and physical properties of the composites [29]. In order to evaluate the surface hydrophobization of jute fabrics via the laccase-mediated grafting of OA, both static and dynamic contact angles

Table 3. Static/dynamic contact angles of jute fabrics after different treatments

\begin{tabular}{|l|c|c|c|}
\hline Treatments & $\begin{array}{c}\text { Static contact } \\
\text { angle } \\
{\left[{ }^{\circ}\right]}\end{array}$ & $\begin{array}{c}\text { Advancing } \\
\text { angle } \\
{\left[{ }^{\circ}\right]}\end{array}$ & $\begin{array}{c}\text { Receding } \\
\text { angle } \\
{\left[{ }^{\circ}\right]}\end{array}$ \\
\hline Laccase/OA & $112.5 \pm 8.1$ & $116.4 \pm 2.0$ & $42.7 \pm 2.8$ \\
\hline Laccase alone & 0.0 & $75.1 \pm 1.8$ & 0.0 \\
\hline Control & 0.0 & $43.5 \pm 0.6$ & 0.0 \\
\hline
\end{tabular}

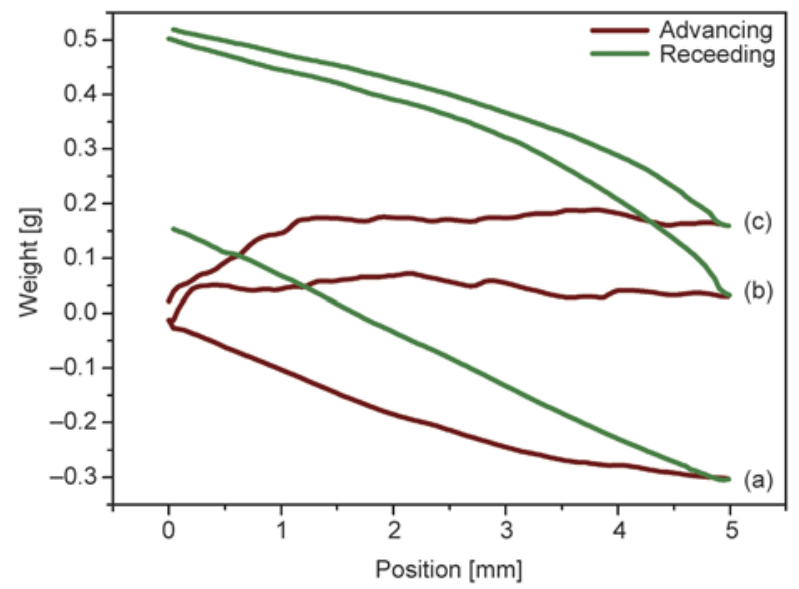

Figure 2. Force curves acting on laccase/OA treated jute fabrics (a), laccase-treated jute fabrics (b) and control jute fabrics (c) when immersed into and withdrawn out of water were measured. The contact angle data were summarized in Table 3 and the force curves acting on jute fabric samples in the Wilhelmy measurement were presented in Figure 2.

For the control and laccase-treated jute fabrics, the water droplets on their surfaces disappeared with no specular reflectance in $3 \mathrm{~s}$. In contrast, the laccase/ OA-treated samples showed an increased static contact angle of $112.5^{\circ}$. However, the static contact angle is not able to explain exactly the dynamic behavior of the surface wettability because of the hysteresis of the contact angle. The dynamic contact angle measurement, based on the Wilhelmy principle, is specially designed to reveal the dynamic process of wetting. When a solid object is immersed into a liquid, the liquid will ascend (hydrophilic) or descend (hydrophobic) along the vertical direction of the solid. The Wilhelmy method measures the pull force or the push force acting on the solid to calculate the dynamic contact angles. According to Huang's description, the relationship between the force acting on samples $(F)$ and the contact angle of samples $(\theta)$ is as followed [30] (Equation (2)):

$F=2 w \cdot t \cdot \sigma \cdot \cos \theta$

where $w$ is the width of the sample and $t$ is the thickness of the sample.

For the control and the laccase-treated jute samples, the advancing angles were 43.5 and $75.1^{\circ}$, respectively. Both of them had no receding angles. By contrast, the laccase/OA-treated samples showed a larger advancing contact angle of $116.4^{\circ}$ and a receding angle of $42.7^{\circ}$. The surface hydrophobic enhancement of jute fabrics after the laccase/OA treatment supported that OA monomers containing nonpolar alkyl chains have been grafted onto the jute fabric surface mediated by laccase.

\subsection{Effect of OA-grafting on thermal properties of jute fabrics}

TGA and DTG curves of the treated jute fabrics and the OA monomer were shown in Figure 3. The OA monomer got its maximum mass loss rate at $245^{\circ} \mathrm{C}$, and there was no solid residue left at $690^{\circ} \mathrm{C}$. The control jute attained the maximum mass loss rate at $388^{\circ} \mathrm{C}$ with $14.1 \%$ residue left at $690^{\circ} \mathrm{C}$. The laccasetreated sample displayed a similar trend as the control sample with the maximum mass loss rate at $389^{\circ} \mathrm{C}$ and $13.1 \%$ residue at $690^{\circ} \mathrm{C}$. For the laccase/ OA treated jute, its thermal resistance was decreased 

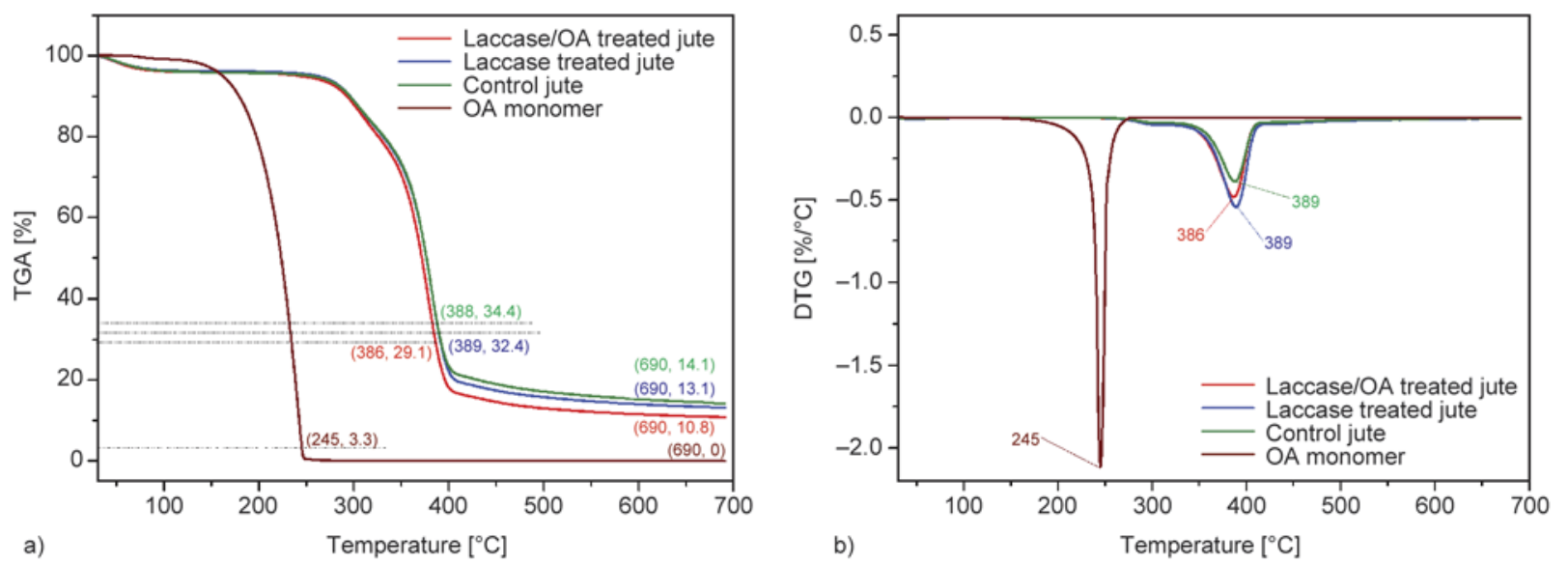

Figure 3. TGA (a) and DTG (b) curves of the treated jute fabrics and the OA monomer

with the maximum mass loss rate at $386^{\circ} \mathrm{C}$ and the solid residue of $10.8 \%$ at $690^{\circ} \mathrm{C}$. This could result from the laccase-mediated grafting of OA molecules with lower thermo-stability onto jute fabrics. However, it should be noted that the enzymatic modification of jute could only occurs on the surface and thus it has slight effects on the thermal properties of the entire jute fabrics.

In addition, the jute was used later to prepare fiberreinforced PP matrix composites at $180^{\circ} \mathrm{C}$ by using hot pressing. According to the thermal data of OA molecules and jute fabrics, their temperatures at the maximum mass loss are both much higher than the temperature of the hot press process. Therefore, the hydrocarbon chains grafted on the jute surface and the jute fabrics wouldn't be damaged or change their chemical structures in the preparation of the jute/PP composites.

\subsection{Interfacial behavior of jute fabric/PP composites}

The fracture surfaces of all the composites were produced by stretching on a universal testing machine and then observed by SEM. The micrographs of the fracture sections were exhibited in Figure 4. The diameter of natural jute fibers is generally 15 $25 \mu \mathrm{m}$ with an oval cavity inside. The areas marked by red circles and rectangles in the SEM images are the ends or tips of jute fibers breaking by the stretching of the jute/PP composites. In the case of the control composites (Figure 4a) and the laccase-treated jute/PP composites (Figure 4b), the tips of fibers were protruded from the polymer matrix and thus the fracture surfaces became uneven and irregular. In addition, there are multitudes of pores normally seen on the tips, which resulted from the breaking and denting of the PP-filled fiber cavities by pulling. For the OA-grafted jute/PP composites (Figure 4c), PP matrix surrounding jute fibers and in the cavities of the fibers was pulled out together with the jute fibers. Jute fibers well adhered to the PP resins to form a neat and smooth fracture surface, indicating the stronger interfacial adhesion of the composites and adequate wetting of fibers with PP resins. While in the other two images, the fibers were pulled out of the polymer matrix during fracturing of the sample, indicating a much weaker interaction between the polymers and the fibers. Therefore, it could be concluded that the modified jute fibers were better coated by PP and stronger fiber-matrix adhesion was obtained owing to the enzymatic hydrophobic modification of the jute surface.

\subsection{Tensile properties of jute fabric/PP composites}

The breaking strength, Young's modulus and elongation at break of the treated jute/PP composites were given in Table 4. Besides, the tensile stressstrain curves of these composites were shown in Figure 5.

The control jute/PP composites showed the lowest breaking strength $(25.6 \mathrm{MPa})$ and Young's modulus (5.4 GPa) among the three types of composites. After the laccase treatment of jute, the breaking strength and the Young's modulus of the composites were increased by 32.8 and $3.7 \%$, respectively. Moreover, the OA-grafted jute/PP composites displayed larger increases in breaking strength and Young's modulus by 82.0 and $22.2 \%$, respectively. These enhancements in tensile strength and modulus of OA-grafted jute/PP composites suggested that the interfacial compatibility of the composites 


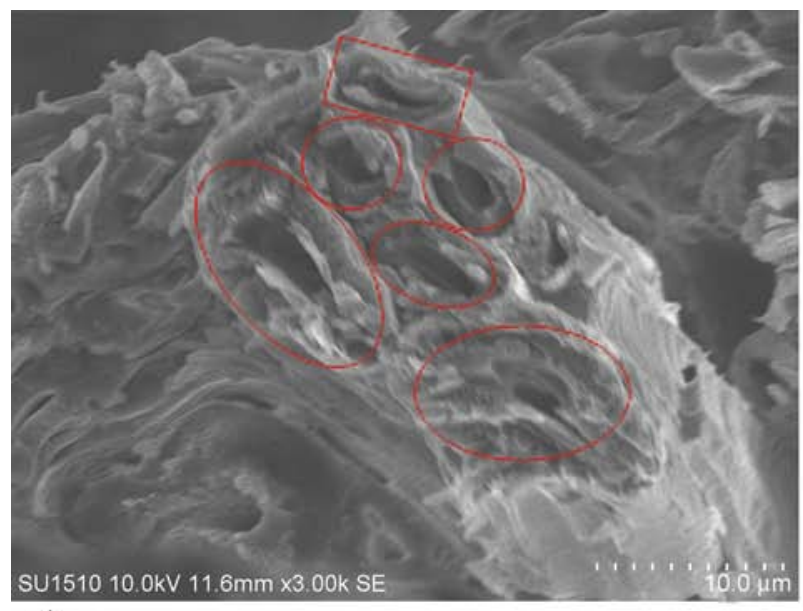

a)

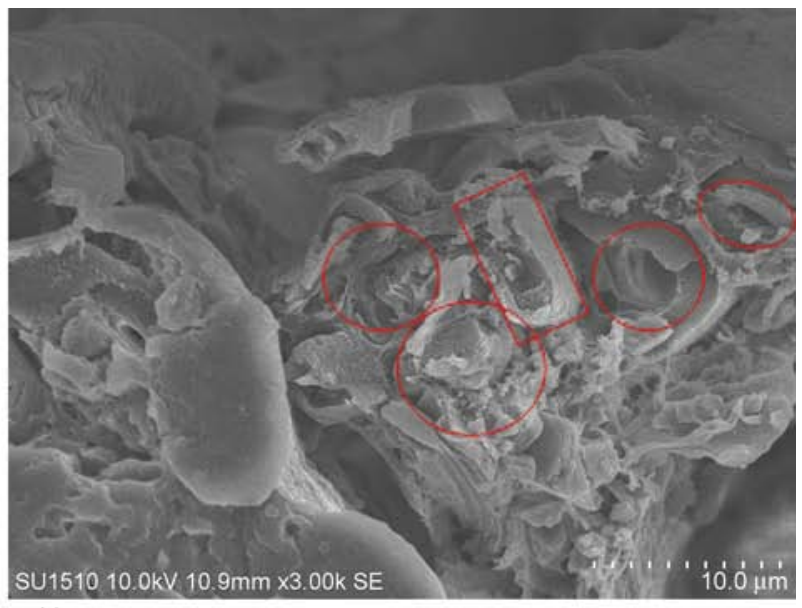

b)

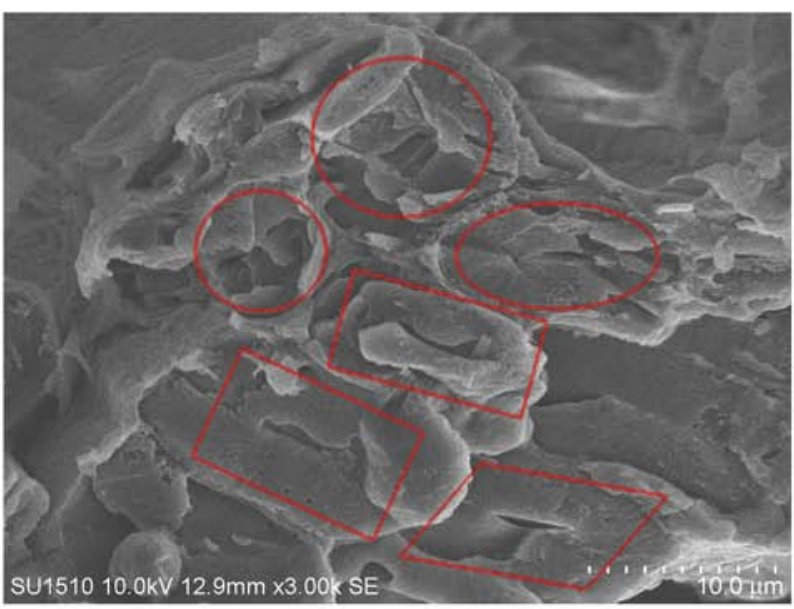

Figure 4. SEM images of fracture sections of control jute fabric/PP composites (a), laccase-treated jute fabric/PP composites (b) and OA-grafted jute fabric/PP composites (c)

Table 4. Mechanical properties of the treated jute/PP composites

\begin{tabular}{|l|c|c|c|}
\hline \multicolumn{1}{|c|}{ Composites } & $\begin{array}{c}\text { Breaking } \\
\text { strength } \\
{[\text { MPa] }}\end{array}$ & $\begin{array}{c}\text { Young's } \\
\text { modulus } \\
{[\text { [GPa] }}\end{array}$ & $\begin{array}{c}\text { Elongation } \\
\text { at break } \\
{[\%]}\end{array}$ \\
\hline Control jute/PP & $25.6 \pm 0.7$ & $5.4 \pm 0.4$ & $1.5 \pm 0.1$ \\
\hline Laccase-treated jute/PP & $34.0 \pm 1.3$ & $5.6 \pm 0.1$ & $2.4 \pm 0.1$ \\
\hline OA-grafted jute/PP & $46.6 \pm 0.9$ & $6.6 \pm 0.2$ & $3.1 \pm 0.1$ \\
\hline
\end{tabular}

was enhanced after the surface hydrophobization of jute fabrics. The long alkyl chains of OA molecules grafted on the jute surface could interact with the PP resins via numerous van der Waals' forces. Therefore, better interfacial adhesion between fibers and hydrophobic resins were obtained, which made the stress to transfer effectively and thus satisfied the requirement of reinforcing the composites with better mechanical properties. In addition, the elongation at break of the enzymatic treated jute/PP composites was also increased. This may be owing to the increase in the elongation at break of jute fabrics after the laccase treatment (no data shown).

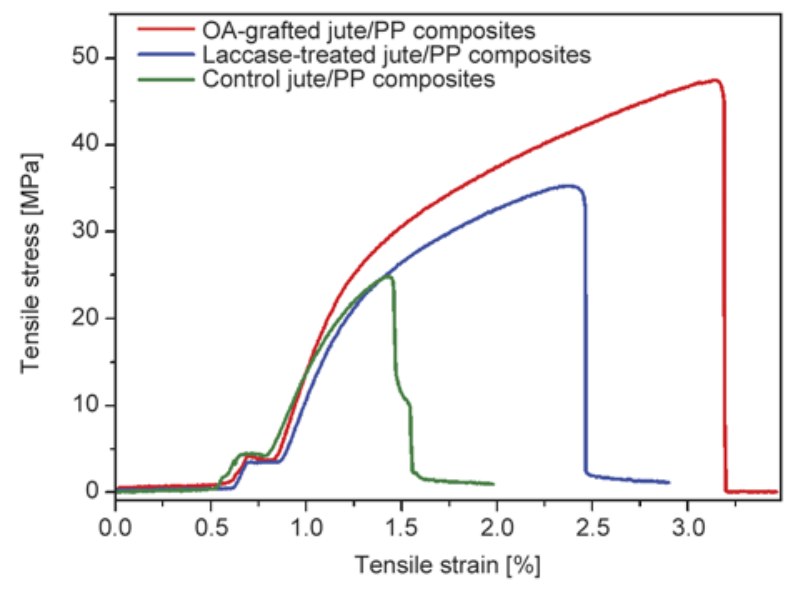

Figure 5. Tensile stress-strain curves of the treated jute fabric/PP composites

\subsection{Dynamic mechanical properties of jute fabric/PP composites}

Dynamic thermo-mechanical properties of the jute fabric/PP composites, storage modulus $\left(E^{\prime}\right)$ and loss modulus $\left(E^{\prime \prime}\right)$ curves as a function of temperature were measured and illustrated in Figure 6. $E^{\prime}$ is very 

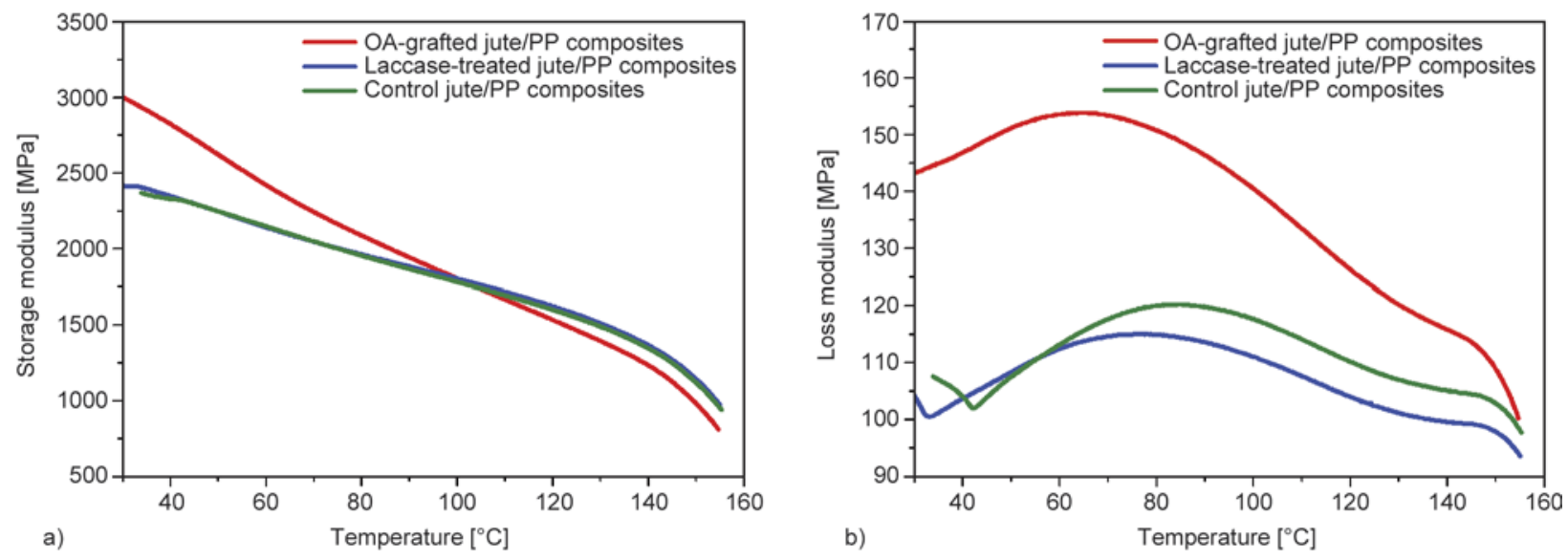

Figure 6. Dynamic mechanical properties of the treated jute fabric/PP composites: Storage (a) and loss modulus (b)

sensitive to the structural and molecular changes of composites, such as fiber-matrix interfacial bonding [31]. The $E^{\prime}$ values of all the composites dropped with the increase of temperature. However, the PP composites reinforced by the OA-grafted jute fabrics had a significant increase in the $E^{\prime}$ before $100^{\circ} \mathrm{C}$ in contrast with the laccase-treated jute/PP composites and the control composites. This can be explained as the result of improved interfacial adhesion between the hydrophobic jute and the PP matrix, which allowed greater stress to transfer at the interface.

As shown in Figure 6b, the OA-grafted jute/PP composites had higher $E^{\prime \prime}$ values in the whole range of testing temperatures than those of the control composites and the laccase-treated jute/PP composites. $E^{\prime \prime}$ is attributed to the mobility of resin molecules in composites [9]. Larger $E^{\prime \prime}$ values suggest stronger restraining effect of fibers on the mobility of the resin matrix. The corresponding increase in $E^{\prime \prime}$ value indicated the restriction was enhanced with the enzymatic hydrophobization of fibers and the fact of immobilization of PP molecules near to the hydrophobic surface of the modified jute fibers. The improved interfacial adhesion reduced the mobility of the PP molecular chain at the interface.

\section{Conclusions}

The present work demonstrated that the covalent attachment of OA onto jute surface mediated by laccase resulted in increases in the surface hydrophobicity of jute fabrics and the interfacial compatibility between jute fibers and PP resins. The surface $\mathrm{C} / \mathrm{O}$ ratio and the total nitrogen content of jute fabrics were increased after the enzymatic grafting, which suggested that OA molecules have been successfully incorporated onto the jute fabric surface mediated by laccase. The $G p$ of the enzymatic OAgrafting reaction was $0.96 \%$. The modified jute obtained excellent water repellency with static contact angle of $112.5^{\circ}$, advancing angle of $116.4^{\circ}$ and receding angle of $42.7^{\circ}$, which supported the presence of nonpolar alkyl chains on the jute surface after the laccase-mediated grafting of OA. No evident decrease of thermal properties was found due to the specificity of laccase to substrates and the surface modification of the enzymatic grafting. The tensile strength, tensile modulus as well as the breaking elongation of the hydrophobized jute/PP composites were increased. The fracture surface of the composites became neat and the jute fibers on the section surface were surrounded by PP resins closely, which suggested better interfacial adhesion between the jute reinforcement and the PP resin.

\section{Acknowledgements}

This work was financially supported by National Natural Science Foundation of China (51173071), Program for New Century Excellent Talents in University (NCET-12-0883), Program for Changjiang Scholars and Innovative Research Team in University (RT_15R26), Fundamental Research Funds for the Central Universities (JUSRP51312B, JUSRP51505).

\section{References}

[1] Wambua P., Ivens J., Verpoest I.: Natural fibres: Can they replace glass in fibre reinforced plastics? Composites Science and Technology, 63, 1259-1264 (2003). DOI: $\underline{10.1016 / \mathrm{S} 0266-3538(03) 00096-4}$

[2] Bledzki A. K., Mamun A. A., Faruk O.: Abaca fibre reinforced PP composites and comparison with jute and flax fibre PP composites. Express Polymer Letters, 1, 755-762 (2007).

DOI: 10.3144/expresspolymlett.2007.104 
[3] Hughes M.: Defects in natural fibres: Their origin, characteristics and implications for natural fibre-reinforced composites. Journal of Materials Science, 47, 599-609 (2012).

DOI: $10.1007 / \mathrm{s} 10853-011-6025-3$

[4] Bledzki A. K., Mamun A. A., Lucka-Gabor M., Gutowski V. S.: The effects of acetylation on properties of flax fibre and its polypropylene composites. Express Polymer Letters, 2, 413-422 (2008).

DOI: $10.3144 /$ expresspolymlett.2008.50

[5] Albanoa C., Reyes J., Ichazo M., González J., Brito M., Moronta D.: Analysis of the mechanical, thermal and morphological behaviour of polypropylene compounds with sisal fibre and wood flour, irradiated with gamma rays. Polymer Degradation and Stability, 76, 191-203 (2002).

DOI: $10.1016 / \mathrm{S} 0141-3910(02) 00014-9$

[6] Yuan X., Jayaraman K., Bhattacharyya D.: Effects of plasma treatment in enhancing the performance of woodfibre-polypropylene composites. Composites Part A: Applied Science and Manufacturing, 35, 13631374 (2004).

DOI: 10.1016/j.compositesa.2004.06.023

[7] Kalia S., Kaith B. S., Kaur I.: Pretreatments of natural fibers and their application as reinforcing material in polymer composites - A review. Polymer Engineering and Science, 49, 1253-1272 (2009).

DOI: $10.1002 /$ pen. 21328

[8] Gassan J., Bledzki A. K.: The influence of fiber-surface treatment on the mechanical properties of jutepolypropylene composites. Composites Part A: Applied Science and Manufacturing, 28, 1001-1005 (1997). DOI: $10.1016 / \mathrm{S} 1359-835 \mathrm{X}(97) 00042-0$

[9] Hong C. K., Hwang I., Kim N., Park D. H., Hwang B. S., Nah C.: Mechanical properties of silanized jutepolypropylene composites. Journal of Industrial and Engineering Chemistry, 14, 71-76 (2008).

DOI: $10.1016 /$ j.jiec.2007.07.002

[10] Hüttermann A., Mai C., Kharazipour A.: Modification of lignin for the production of new compounded materials. Applied Microbiology and Biotechnology, 55, 387-394 (2001).

DOI: $10.1007 / \mathrm{s} 002530000590$

[11] Nyanhongo G. S., Kudanga T., Prasetyo E. N., Gübitz G. M.: Enzymatic polymer functionalisation: Advances in laccase and peroxidase derived lignocellulose functional polymers. Advances in Biochemical Engineering/Biotechnology, 125, 47-68 (2011).

DOI: $10.1007 / 102010 \quad 86$

[12] Kudanga T., Prasetyo E. N., Sipilä J., Nyanhongo G. S., Guebitz G. M.: Chemo-enzymatic functionalisation of lignocellulose materials using oxiranes. Process Biochemistry, 45, 1557-1562 (2010).

DOI: $10.1016 /$ j.procbio.2010.06.008
[13] Aracri E., Colom J. F., Vidal T.: Application of laccase-natural mediator systems to sisal pulp: An effective approach to biobleaching or functionalizing pulp fibres? Bioresource Technology, 100, 5911-5916 (2009).

DOI: 10.1016/j.biortech.2009.06.016

[14] Zhou H., Yang D., Qiu X., Wu X., Li Y.: A novel and efficient polymerization of lignosulfonates by horseradish peroxidase $/ \mathrm{H}_{2} \mathrm{O}_{2}$ incubation. Applied Microbiology and Biotechnology, 97, 10309-10320 (2013). DOI: $10.1007 / \mathrm{s} 00253-013-5267-1$

[15] Claus H.: Laccases: structure, reactions, distribution. Micron, 35, 93-96 (2004).

DOI: $10.1016 /$ j.micron.2003.10.029

[16] Riva S.: Laccases: Blue enzymes for green chemistry. Trends in Biotechnology, 24, 219-226 (2006). DOI: $10.1016 /$ j.tibtech.2006.03.006

[17] Lahtinen M., Kruus K., Heinonen P., Sipilä J.: On the reactions of two fungal laccases differing in their redox potential with lignin model compounds: Products and their rate of formation. Journal of Agricultural and Food Chemistry, 57, 8357-8365 (2009). DOI: $10.1021 / \mathrm{jf} 901511 \mathrm{k}$

[18] Kudanga T., Prasetyo E. N., Widsten P., Kandelbauer A., Jury S., Heathcote C., Sipilä J., Weber H., Nyanhongo G. S., Guebitz G. M.: Laccase catalyzed covalent coupling of fluorophenols increases lignocellulose surface hydrophobicity. Bioresource Technology, 101, 27932799 (2010).

DOI: 10.1016/j.biortech.2009.12.002

[19] Widsten P., Heathcote C., Kandelbauer A., Guebitz G., Nyanhongo G. S., Prasetyo E. N., Kudanga T.: Enzymatic surface functionalisation of lignocellulosic materials with tannins for enhancing antibacterial properties. Process Biochemistry, 45, 1072-1081 (2010). DOI: $10.1016 /$ j.procbio.2010.03.022

[20] Garcia-Ubasart J., Vidal T., Torres A. L., Rojas O. J.: Laccase-mediated coupling of nonpolar chains for the hydrophobization of lignocellulose. Biomacromolecules, 14, 1637-1644 (2013).

DOI: $10.1021 / \mathrm{bm} 400291 \mathrm{~s}$

[21] Fillat A., Gallardo O., Vidal T., Pastor F. I. J., Díaz P., Roncero M. B.: Enzymatic grafting of natural phenols to flax fibres: Development of antimicrobial properties. Carbohydrate Polymers, 87, 146-152 (2012). DOI: $10.1016 /$ j.carbpol.2011.07.030

[22] Liu N., Shi S. L., Gao Y., Qin M.: Fiber modification of kraft pulp with laccase in presence of methyl syringate. Enzyme and Microbial Technology, 44, 8995 (2009).

DOI: 10.1016/j.enzmictec.2008.10.014

[23] Dong A., Yu Y., Yuan J., Wang Q., Fan X.: Hydrophobic modification of jute fiber used for composite reinforcement via laccase-mediated grafting. Applied Surface Science, 301, 418-427 (2014). DOI: $\underline{10.1016 / \mathrm{j} . \text { apsusc. } 2014.02 .092}$ 
[24] Dong A., Yu Y., Fan X., Wang Q., Cavaco-Paulo A.: Enzymatic coating of jute fabrics for enhancing antiultraviolent properties via in-situ polymerization of polyhydric phenols. Journal of Industrial Textiles, in press (2016).

DOI: $10.1177 / 1528083715577935$

[25] Thakur K., Kalia S., Kaith B. S., Pathania D., Kumar A.: Surface functionalization of coconut fibers by enzymatic biografting of syringaldehyde for the development of biocomposites. RSC Advances, 5, 76844-76851 (2015).

DOI: $10.1039 / \mathrm{c} 5 \mathrm{ra} 14891 \mathrm{j}$

[26] Kudanga T., Prasetyo E. N., Sipilä J., Guebitz G. M., Nyanhongo G. S.: Reactivity of long chain alkylamines to lignin moieties: Implications on hydrophobicity of lignocellulose materials. Journal of Biotechnology, 149, 81-87 (2010).

DOI: $10.1016 /$ j.jbiotec.2010.06.020

[27] Childs R., Bardsley W.: The steady-state kinetics of peroxidase with 2,2'-azino-di-(3-ethylbenzthiazoline6-sulphonic acid) as chromogen. Biochemical Journal, 145, 93-103 (1975).

DOI: $10.1042 /$ bj 1450093
[28] Ramamoorthy S. K., Bakare F., Herrmann R., Skrifvars M.: Performance of biocomposites from surface modified regenerated cellulose fibers and lactic acid thermoset bioresin. Cellulose, 22, 2507-2528 (2015). DOI: $10.1007 / \mathrm{s} 10570-015-0643-\mathrm{X}$

[29] Ramamoorthy S. K., Di Q., Adekunle K., Skrifvars M.: Effect of water absorption on mechanical properties of soybean oil thermosets reinforced with natural fibers. Journal of Reinforced Plastics and Composites, 31, 1191-1200 (2012). DOI: $10.1177 / 0731684412455257$

[30] Huang F., Wei Q., Wang X., Xu W.: Dynamic contact angles and morphology of PP fibres treated with plasma. Polymer Testing, 25, 22-27 (2006).

DOI: $10.1016 / \mathrm{j}$. polymertesting.2005.09.017

[31] Jacob M., Francis B., Thomas S.: Dynamical mechanical analysis of sisal/oil palm hybrid fiber-reinforced natural rubber composites. Polymer Composites, 27, 671-680 (2006).

DOI: $10.1002 /$ pc. 20250 